\title{
Is the Computer Going to Take Over from the Composer?
}

Norman A. Macleod

Cheltenham, England

(In my article published in Vo1. 5, No. 2, "How the Computer Helps the Composer", I had the pleasure of quoting a fourfold twin from Norman A. Macleod, a helpmate in three, composed not by the author but by his program "Composer". How he did it and what other difficulties arose in the display of "Composer" are described in the following interesting paper. - Laszlo Lindner)

The computer program COMPOSER is in theory capable of producing all orthodox problems up to the size of a miniature ( 7 men). In practice, time and storage considerations make it impractical to deal exhaustively with problems containing more than 3 or 4 men. So far I have dealt mainly with problems with only 3 men. The following genres were-considered: directmates, direct stalemates, helpmates, helpstalemates, seriesmates, seriesstalemates, serieshelpmates, and serieshelpstalemates.

My results contain a small percentage of inaccuracy due to program errors that I have not yet been able to correct. In the case of directmates and stalemates, demands on storage restricted the length of problems that could be considered. For mates using $K / R \& K$, up to $\neq 9 ; K / Q \& K$, up to $\neq 6$. For stalemates, $\mathrm{K} / \mathrm{R} \& \mathrm{~K}$, up to $=7 ; \mathrm{K} / \mathrm{Q} \& \mathrm{~K}$, up to $=4$. For both types, $\mathrm{K} / \mathrm{P} \& \mathrm{~K}$ has not yet been dealt with. Otherwise, all problems of any length for all types have been produced. The output of the program consists of all distinct positions (with respect to reflection and rotation) with a single accurate solution.

(Note: "reflection" means flip-flopping the board, left-half to right-half. In "rotation" in pawnless settings, the same position can be duplicated effectively with any quarter turn of the board. Actually, in a pawnless setting, and with reference to whether the "mated" king starts or ends on $x$ square, this square can be limited to a 10 square area: al to d4 to dl to al. The other pieces can then be set in unique relationships, except for those cases where asymmetric "reflections" occur on the al-h8 diagonal. - Ed.)

In the case of directmates and stalemates this means a solution with at least one dual free variation. The numbers produced for each type were as follows :

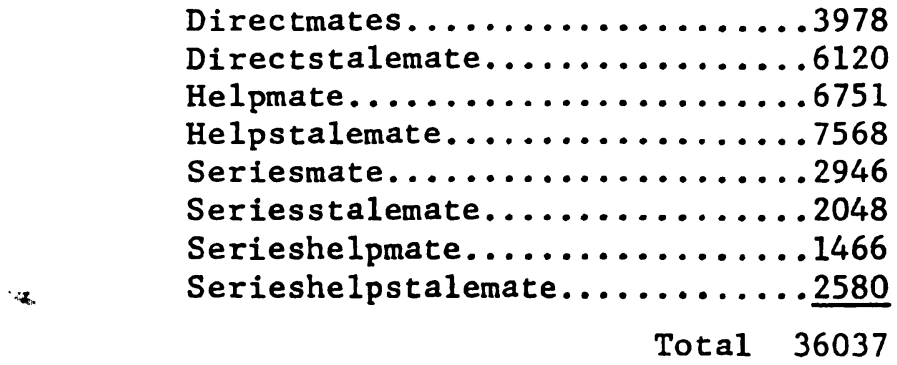

Of course, the number of distinct problems is much less than this number since, although reflections and rotations have been eliminated, it is often the case that all three men may be shifted on the board without change to 
the problem, or there may be optional squares for any of the three men, again without changing the problem.

So where are the gems among this large number of positions to be looked at?

Clearly, it would be pointless to publish the entire set. The task of looking through the computer output to find problems of value is almost as great as that of the composer who is looking for 3-man settings without the aid of a computer! In any case, such problems are not composed; they are already there! It is simply a maiter of finding them. Of course, it is easy to check the length records.

For helpstalemates, nothing longer than $\mathrm{H}=4$ was found, but on examining the record $\mathrm{H}=5$ by $\mathrm{J}$. Ban, I found it to be cooked. A small selection from the computer's output follows. To help in the task of finding interesting settings, I used supplementary routines on the computer; for example, to look for twins (only one man moved, piece replacement, rotation of the board, same position for two different types, etc.).

The method used by the program is first to find all final positions ( $\neq$ or $\Rightarrow$ ) for each combination of pieces. Then the program makes all possible retromoves. The resulting positions are sorted and duplications removed. Positions without a duplicate are designated "good" and those with a duplicate "bad". Retro-moves must be made from both "good" and "bad" positions, but all ancestors of "bad" positions are "bad". Nonduplicated ancestors of "good" positions are "good". A slight variation of this procedure is needed for directmates and stalemates. Another variation was added to produce accurate multi-solution problems.

The program is capable of producing the exhaustive set of 4-man problems but the number of distinct positions would be large - I would guess on the order of 1,000,000. Also, the computer time and disk storage needed would be considerable, though not out of the question for the facilities of a university or other research establishment.

So, is the computer going to take over from the composer as well as the solver? I think not! The unexpectedly large numbers, even for problems with very few men, show that there is no chance at all of the computer exhausting the field even of miniatures, let alone problems without restriction on the number of men. The fact that the computer has made new finds in 3-man settings makes nonsense of any claim that such and such a field (for example, the orthodox 2-mover) is exhausted.

Norman A. Macleod Dunvegan, Oakley Road Cheltenham GL52 6PA

Dr. Laszlo Lindner

Nepkoztarsasag utja 54

H-1062 Budapest, Hungary 
1.

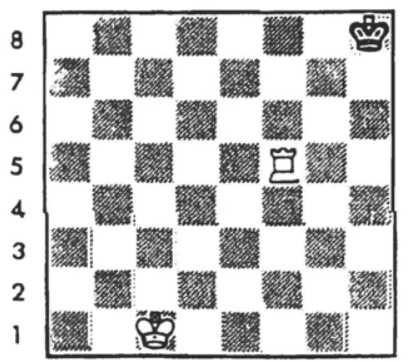

$a b c d$ e $f g h$

f9 b)BKh7 c)WKa5
2.

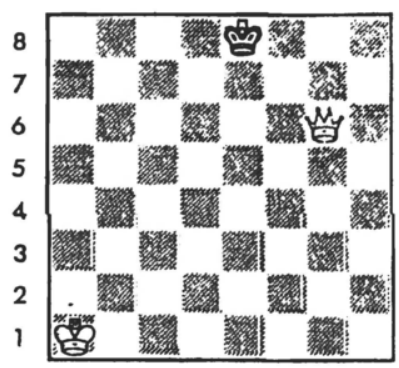

a b c d e f g h

$\mathrm{H} \neq 4$ b)'WKh?
3.

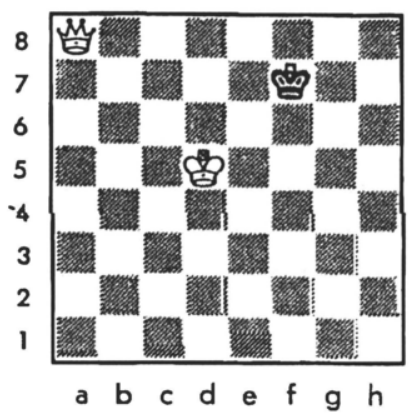

Stalemate in 4
4.

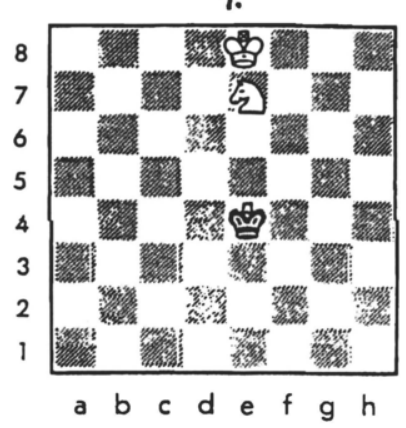

$\mathrm{H}=4$ b) Sa 5 c) ikc1

d) WKC4 e) further sd 5

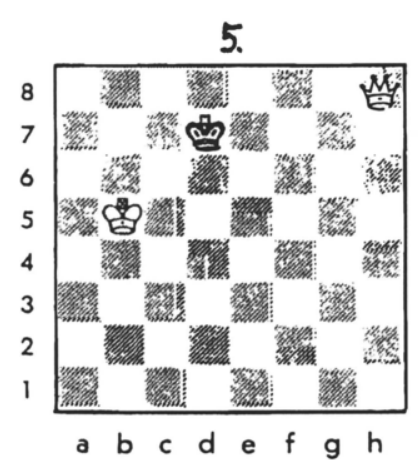

$\because=2$ b)WKf6

d) $2 \mathrm{~b} 7$

c) $2 \mathrm{~h} 7$

9.

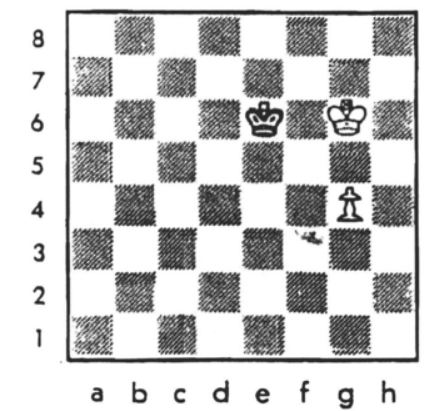

$\therefore=4 \quad$ b) WKh 8
6.

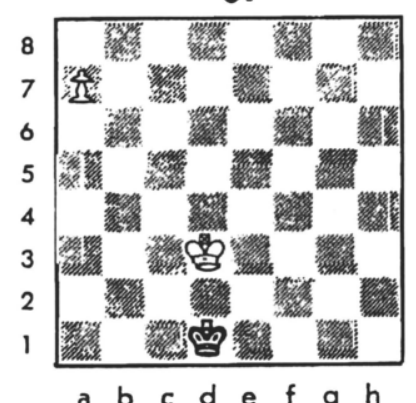

$\mathrm{H}=2$ with set play b) $\mathrm{Pb} 7$

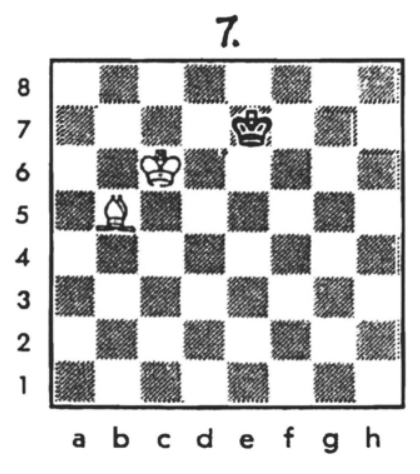

$\mathrm{H}=3$ white to move $\begin{array}{ll}\text { b) } 3 K e 6 & \text { c) WKg? }\end{array}$
8.

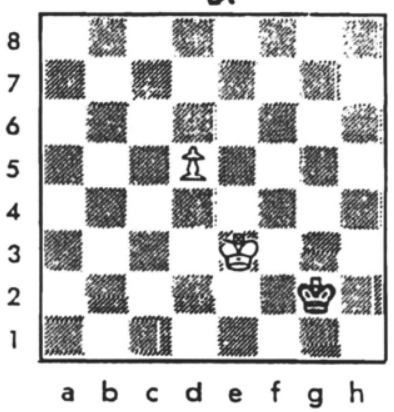

$\mathrm{H}=4 \mathrm{~b}) \operatorname{turn} 180^{\circ}$ c) turn $90^{\circ}$ clockwise
10.

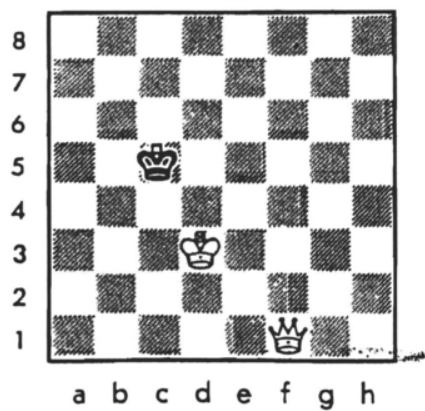

(i) $\mathrm{H} \neq 2$ (ii) $\mathrm{H}=2$ b) $2 \mathrm{~d} 8$
11.

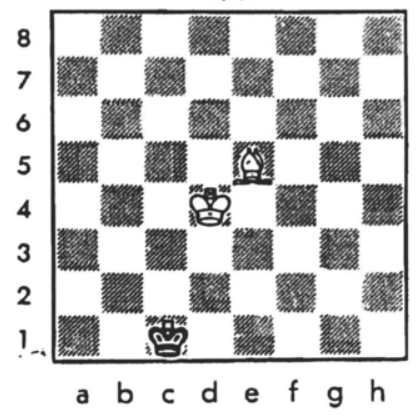

$\mathrm{H} \neq 3$ white to move ( 3 solutions)
12.

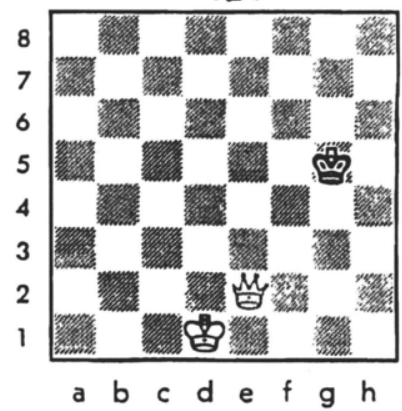

$H \neq 3$

b) $\mathrm{H}=3$ 
SOLUTIONS TO PROBLEMS FOUND BY "COMPOSER":

1) (a) $1 . \mathrm{Kd} 2 ! \mathrm{Kh} 7,2 . \mathrm{Ke} 3 \mathrm{Kg} 7,3 . \mathrm{Kf} 4 \mathrm{Kg} 6,4 . \mathrm{Kg} 4 \mathrm{Kh} 6,5 . \mathrm{Rg} 5 \mathrm{~Kb} 7,6 . \mathrm{Kh} 5 \mathrm{Kh} 8$, $7 . \mathrm{Kg} 6 \mathrm{Kg} 8,8 . \mathrm{Rf} 5$.

(b) 1.Rg5! Kh6, 2.Rg1! Kh5, 3.Kd2 Kh4, 4.Ke3 Kh5, 5.Kf4 Kh6, 6.Kf5 Kh7, 7.Kf6 Kh8, 8.Kf7. 4...Kh3, 5.Kf4 Kh2, 6.Rg3 Kh1, 7.Ke3/f3 Kh2, 8.Kf2.

(c) 1.Rf7! Kg8, 2.Rd7! Kf8, 3.Kb6 Ke8, 4.Kc7 Kf8, 5.Kd8 Kg8, 6.Ke8 Kh8, 7.Kf7 Kh7, 8.Rd6. Different strategy in each part.

2) (a) $1 . \mathrm{Kd} 7 \mathrm{Qb} 1,2 . \mathrm{Kc} 6 \mathrm{~Kb} 2,3 . \mathrm{Kb} 5 \mathrm{Kc} 3,4 . \mathrm{Ka} 4.2 \mathrm{~b} 4 \neq$ (b) $1 . \mathrm{Ke} 7 \mathrm{2g} 1,2 . \mathrm{Kf} 6 \mathrm{Kg} 2,3 . \mathrm{Kg} 5 \mathrm{Kf} 3+, 4 . \mathrm{Kh} 42 \mathrm{~g} 4 \neq$ The WQ has to make a long move in order for the WK to intercept it. I think the best of this set, not easy to solve.

3) $1 . \mathrm{Ke} 5 \mathrm{Kg} 6,2.2 \mathrm{f} 8 \mathrm{KE}, 5,3.2 \mathrm{f} 5+1 \ldots \mathrm{Kg}$, 2.2e8 Kh6, 3.Kf6. 1...Ke7, 2.Qd5 Kf8, 3.Kf6. Three accurate variations.

4) (a) $1 . \mathrm{Ke} 5 \mathrm{Sg} 6+, 2 . \mathrm{Kf} 6 \mathrm{Sf} 8,3 . \mathrm{Kg} 7 \mathrm{Ke} 7,4 . \mathrm{Kh} 8 \mathrm{Kf} 7=$ (b) $1 . \mathrm{Kf} 5 \mathrm{Sc} 6,2 . \mathrm{Kg} 6 \mathrm{Se} 7+, 3 . \mathrm{Kh} 7 \mathrm{Kf7}, 4 . \mathrm{Kh} 8 \mathrm{Kg} 6=$

(c) $1 . \mathrm{Kd} 3 \mathrm{Ka} 2,2 . \mathrm{Kc2} \mathrm{Ka} 3,3 . \mathrm{Kb} 1 \mathrm{Sd} 5,4 . \mathrm{Ka} 1 \mathrm{Sc} 3=$

(d) $1 . \mathrm{Ke} 5 \mathrm{Kd} 3,2 . \mathrm{Kf} 6 \mathrm{Ke} 4,3 . \mathrm{Kg} 7 \mathrm{Kf5}, 4 . \mathrm{Kh} 8 \mathrm{Kg} 6=$ (e) 1.Kf5 Sf6, 2.Kg6 Kd5, 3.Kg7 Ke6, 4.Kh8 Kf7= Five different stalemate settings with $\mathrm{K} / \mathrm{s}$.

5) (a) $1 . \mathrm{Ke} 7 \mathrm{Qf} 6+, 2 . \mathrm{Ke} 8 \mathrm{Kc} 6=$ (b) $1 . \mathrm{Kc7} 2 \mathrm{h1}, 2 . \mathrm{Kd} 8 \mathrm{2c} 6=$ (a) $1 . \mathrm{Ke} 8 \mathrm{Kc} 6,2 . \mathrm{Kf} 8 \mathrm{Ke} 7=$ $\mathrm{BK}$ stalemated on four different squares.

6) (a) $1 \ldots \mathrm{Pa} 8 \mathrm{2}, 2 . \mathrm{Ke} 1 \mathrm{2f} 3=1 . \mathrm{Kc1} \mathrm{Pa} 82,2 . \mathrm{Kb} 1 \mathrm{Qa} 3=$ (b) $1 \ldots \mathrm{Pb} 82,2 \cdot \mathrm{Kc1} 2 \mathrm{~b} 3=1 . \mathrm{Ke1} \mathrm{Pb} 82,2 \cdot \mathrm{Kf1} \mathrm{Qg} 3=$

7) (a) $1 \ldots \mathrm{Ba} 4 ! 2 . \mathrm{Ke} 8 \mathrm{Kd} 6,3 . \mathrm{Kd} 8 \mathrm{Bd} 7=$ Tempo move by $W$ piece. (b) $1 \ldots \mathrm{Kd} 5,2 . \mathrm{Ke} 7 \mathrm{Bd} 7,3 . \mathrm{Kd} 8 \mathrm{Kd} 6=$ Tempo move by $\mathrm{W} \mathrm{king}$. (c) $1 \ldots \mathrm{Bc} 4,2 . \mathrm{Ke} 8 \mathrm{Kf} 6,3 . \mathrm{Kf} 8 \mathrm{Bf} 7=$

8) (a) $1 \ldots \mathrm{Pd} 6,2 . \mathrm{Kg1} ! \mathrm{Pd} 7,3 . \mathrm{Kf1} \mathrm{Pd} 8 \mathrm{2}, 4 . \mathrm{Ke1} \mathrm{Qd} 3=$

(b) $1 \ldots \mathrm{Pe} 5,2 . \mathrm{Kc} 8 \mathrm{Pe} 6,3 . \mathrm{Kd} 8 \mathrm{Pe} 7+, 4 . \mathrm{Ke} 8 \mathrm{Ke} 6=$

(c) $1 \ldots$ Pe6, 2.Ka3 Pe7, 3.Ka4 Pe82t, $4 . \mathrm{Ka} 5 \mathrm{Qc6}=$

The only rotational 3-man triplet.

9) (a) $1 . \mathrm{Ke} 7 \mathrm{Pg} 5,2 . \mathrm{Kf} 8 \mathrm{Kf} 6,3 . \mathrm{Kg} 8 \mathrm{Pg} 6,4 . \mathrm{Kh} 8 \mathrm{Kf} 7=$ (b) $1 . \mathrm{Kf} 6 \mathrm{Kg} 8,2 . \mathrm{Kg} 6 \mathrm{Kf} 8,3 . \mathrm{Kh} 7 \mathrm{Pg} 5,4 . \mathrm{Kh} 8 \mathrm{Pg} 6=$

10) (a) (i) $1 . \mathrm{Kb} 5 \mathrm{Kc} 3+, 2 . \mathrm{Ka} 4 \mathrm{2a} 6 \neq$ (ii) $1 . \mathrm{Kb} 4 \mathrm{Kc2}, 2 . \mathrm{Ka} 3$ 2c4= (b) (i) $1 . \mathrm{Kb} 4 \mathrm{Kc2}, 2 . \mathrm{Ka} 3$ 2a $5 \neq$ (ii) $1 . \mathrm{Kb} 52 \mathrm{c7}, 2 . \mathrm{Ka} 6 \mathrm{Kc} 4=$ Reciprocal change.

11) $1 . . \mathrm{Bf} 4+, 2 . \mathrm{Kc2} \mathrm{Bd} 2,3 . \mathrm{Kd} 1 \mathrm{Kd} 3=1 \ldots \mathrm{Kc4}, 2 . \mathrm{Kc2} \mathrm{Bb} 2,3 . \mathrm{Kb} 1 \mathrm{~Kb} 3=$ $1 \ldots \mathrm{Kd} 3,2 . \mathrm{Kb} 1 \mathrm{Bb} 2,3 . \mathrm{Ka} 2 \mathrm{Kc2}=$ Problems with three accurate solutions are rare.

.2) (a) $1 \ldots \mathrm{Ke} 1,2 . \mathrm{Kh} 4 \mathrm{Kf} 2,3 . \mathrm{Kh} 3 \mathrm{2h} 5 \neq$

(b) $1 \ldots 2 f 2,2 . \mathrm{Kg}_{4} \mathrm{Ke} 2,3 . \mathrm{Kh} 3 \mathrm{Kf3}=$

Afrother possibility of the theme shown is doubled \#10.

Note: In order to ensure accuracy, the above solutions were not retyped. 